\title{
The Secret to Remote Work - Results of a Case Study with Dyadic Interviews
}

\author{
Nadine Ratz \\ Fujitsu TDS GmbH \\ nadine.ratz@yahoo.de
}

\author{
Victoria Reibenspiess \\ GGS Heilbronn \\ victoria.reibenspiess@ggs.de
}

\author{
Andreas Eckhardt \\ University of Innsbruck \\ andreas.eckhardt@uibk.ac.at
}

\begin{abstract}
Remote workers can offer significant benefits, but many organizations that have tried this approach have failed because they do not entirely understand these workers and their work environment. Based on the remote working concept of a large global information and communication technology (ICT) company, in our case study containing dyadic interviews (i.e., pairs of a manager and an employee), we consider the positive and negative aspects of remote work and strive to find out how these workers adapt to their work environment. In particular, we scrutinize the work life of remote workers, as well as the opinions of their managers regarding social and workplace isolation, self-determination, collegial support, work opportunities, as well as the productivity and obligations towards their employer. The findings reveal that remote workers have different coping mechanisms, but most have a high degree of autonomy. Additionally, many lack social contacts and feel a certain degree of isolation. Thus, not everyone who works remotely likes it.
\end{abstract}

\section{Introduction}

Work-life has many different facets. Some people work half-time, others full. Some employees work at their customer's locations, while others work at their companies' locations. Some work partly from home and partly from another place, and some work from home the whole time. However, not every employer can offer all workplace possibilities to their employees.

Nonetheless, one concept that is advancing worldwide is working from home [1]. Employees seem to like the possibility [2], and employers see advantages to remote work $^{1}$ as well [3]; otherwise, they would not offer such opportunities [3].

Remote work is on the rise. A couple of years ago, companies had a competitive advantage if they offered remote working opportunities [4-5]. Today, in times of a

${ }^{1}$ The terms remote work and home office have the same meaning. global pandemic (COVID-19), it becomes a necessity, and thus both employees and employers request remote work possibilities $[1,23]$. Therefore, many companies just jump into remote working concepts for their company and their employees [4]. Despite a significant number of unsuccessful remote work initiatives, some companies have already succeeded in implementing remote work arrangements $[1,6]$. There are a couple of reasons why some remote working concepts work, and others do not. One possibility is that the infrastructure is not elaborate enough to support remote workers [1]. Another is that the company provides remote working contracts, but lacks all the steps in this process [4]. Another possibility might be that the employees need to have a particular attitude if they want to effectively work from home [1, 7-8]. Hence, the reasons are manifold as to why remote working concepts might or might not work.

Nevertheless, as the employee is one of the most critical parts of a remote working concept, in this study, we look into the life of remote workers. Therefore, we formulate the following research question:

$R Q:$ How do remote workers adapt to their working situation?

\section{Research Background: Remote Work}

Many companies around the world have now, due to COVID-19, implemented the concept of working from home [23]. Working from home (also called remote work) is possible only for jobs where the employee can work independently from a specific location.

Working from home can have different characteristics. For example, some companies implement telework as a type of remote work. Within this concept, the employee works partly from home and partly from a company facility. Other companies implement remote work in its full dimension, which means that the employee works solely from home. However, there is no universal and precise definition of remote work, and its measurement covers a variety of different situations in terms of technology used, location, contractual arrangement, and time intensity [4]. Therefore, we define remote work in our context as follows: Employees who work from home and have no dedicated workspace at a company's 
location. They, however, have the same or similar tasks as their colleagues who work in-house, and they work within the regular working time.

Studies have detected different dimensions of remote work [9]. The most commonly investigated dimensions of remote work within these articles can be clustered into five areas $^{2}$ : 1) positive and negative aspects of remote work, 2) social and workplace isolation, 3) selfdetermination, 4) support from colleagues and work opportunities, and 5) productivity and obligations towards the company.

The first area is the positive and negative aspects of remote work. Menezes and Kelliher [10] show that remote workers have higher job satisfaction. In contrast, Eddleston and Mulki [11] show that remote workers tend to overwork and that remote workers have difficulties in separating their work life from their private life. If the work-life of a remote worker is embedded in one's home, work can physically and psychologically intrude upon family life. Thus, habits and norms are formed that may induce remote workers to be preoccupied with work when home [11]. Hence, remote workers may find it more difficult to maintain a work-life friendly environment. Koch and Binnewies [12] state that if employees are always-on, and they think that their organization expects this, they feel unfairly treated by disproportionate expectations of work-home integration. However, remote work mostly allows the employee to work more flexible, which seems to be a positive aspect, but blurs the line between always-on and flexible work time. However, Grant et al. [8] claim that the positive aspects of remote work lead to an increase in productivity. In the literature, studies give an overview of the advantages and disadvantages of remote work [8-11]. However, the findings suggest that there may be more disadvantages than advantages. Thus, in this study, we examine why employees want to work remotely, and if the positive and negative aspects are as unbalanced as they seem.

The second area is social and workplace isolation. Orhan et al. [13] find that workplace isolation can entail social isolation. Other studies elaborate on the importance of workplace relationships (e.g., [14]). Workplace relationships stand contrary to social isolation [15]. If an employee is socially isolated, the individual might not be able to foster workplace relationships [15]. However, workplace isolation does not necessarily hamper workplace relationships as much as social isolation does. Marshall et al. [16] describe workplace isolation as an employee's perceptions as the lack of support and recognition, missed opportunities for informal interactions with co-workers, and not being part of the group. Orhan et al. [13], on the other hand, state that physical distance is the cause of workplace isolation. However, both studies

\footnotetext{
2 Some dimensions are overlap, e.g., the 'positive and negative aspects' are overlapping with the dimension self-determination. Our objective was to emphasize the chosen focus of earlier studies (e.g., focus was mainly on investigating negative and positive aspects of remote work as on one special dimension like workplace isolation).
}

relate that workplace isolation can have a negative influence on employees. Marshall et al. [16] find that workplace isolation has a negative correlation towards different attitudes, such as satisfaction. Orhan et al. [13] add hat higher isolation and increased feelings of being deprived of information and access to key people affect satisfaction and performance. Social isolation has different distinctions, such as relatedness and active rejection [2]. Thus, a distinction needs to be made between the lack of need fulfillment and the experience of need frustration [2]. In regard to the latter, need frustration implicates negative facets like ill-being or passivity [2]. However, even social isolation can have positive facets. Grant et al. [8] find that some remote workers like having a quiet private space to work with no interruptions. Nonetheless, findings suggest that workplace relationships are essential for employees (e.g., [14]). Colbert et al. [14] show that having friends at work has positive facets, such as fostering employees' positive feelings. Thus, in this study, we examine the perceived workplace and social isolation of remote workers and their implications, especially on workplace relationships.

The third area is self-determination. Self-determination theory relates to psychological needs (competence, relatedness, autonomy) that are the basis for motivation [17]. Remote work might deprive employees of workplace relationships [17]. People thus might argue that employees who work remotely need other sources to compensate for the lack of workplace relationships [13]. Ryan and Deci [17] claim that the fullest representations of humanity depict people as curious, vital, and self-motivated. In other words, this could imply that every organization should strive to employ people who inherit the fullest representation of humanity, as this indicates that they are the most valuable type for a company [17].

Moreover, the work environment is an essential part of employee motivation and behavior. However, the work environment of a remote worker is different due to the absence of face-to-face contact. Thus, in our study, we investigate how remote workers adapt to the lack of direct social contact and whether or not it influences their motivation and behavior.

Furthermore, Ryan and Deci [17] argue that the social context influences non-intrinsic motivation. Contexts supportive of autonomy, competence, and relatedness foster greater internalization and integration than contexts that thwart the satisfaction of these needs [17]. The motivation remote workers get from colleagues, and especially supervisors, heavily relies on the worker's autonomy [18]. Vander Elst et al. [18] suggest that if employees have a lower level of autonomy, they have fewer opportunities to make decisions, which can lead to frustration. On the other hand, Grant et al. [8] argue that remote workers who have greater autonomy than on-site workers require less supervision. Overall, the need for autonomy is integral to the development and sustenance of intrinsically motivated activities [2]. Thus, in this study, we examine whether employees feel their psychological 
needs (e.g., autonomy) are satisfied and why they believe so.

The fourth area of research is support from colleagues and work opportunities. Remote workers might have less visibility and get less coaching than employees who work on-site [19]. De Menezes and Kelliher [10] suggest that less supervision can result in poor performance. Perry et al. [19] suggest that managers should consider how to support remote workers even before they start working from home. However, less supervision can come with greater autonomy, because the remote worker can manage theirself quite well [8]. Phrasing it another way: if the remote worker feels a higher level of supervision than they think might be necessary, the need for autonomy can be frustrating. Thus, a manager needs to find a balance between too much and too little supervision. However, managers should enhance their communications with remote workers, and they should regularly check on workload, well-being, and performance as well [8]. Additionally, communication and support from colleagues emerge as two critical success factors to ensure effective remote working and to balance the psychological aspects of worker well-being [8]. Thus, in this study, we examine what support remote workers get from colleagues and supervisors, and if the support is sufficient.

The fifth area is productivity and obligations towards the company. Most of the studies investigating remote work and productivity agree that productivity increases [4], [8]. Grant et al. [8] claim that productivity increases for the following reasons: (1) working quietly without interruption, (2) avoidance of social processes in the office, and (3) none of the problems associated with working in an open-plan office, such as noise and lack of privacy. However, Eddleston and Mulki [11] argue that family accessibility might hamper the productivity of the remote worker. Thus, productivity can be influenced by different factors, which is why we examine the different perceptions or remote working and how they influence performance.

Another point to consider is feelings of obligations towards the company. A remote worker might want to give something back because they can work remotely. Chiniara and Bentein [20] claim that if the need for relatedness is satisfied, an employee might feel the need to reciprocate by working longer or putting more effort into tasks. However, if people feel their psychological needs are unsatisfied, they can act defensively [2]. This means that if organizations are unable to satisfy employees' psychological needs, they may under-work [8]. Thus, in this study, we examine how remote workers perceive their productivity and if they feel an obligation toward their employer.

\section{Research Methodology}

In our case study with dyadic interviews, we investigate a global information and communication technology company. The organization has 140,365 employees and supports customers in more than 100 countries. The overall turnover was around 32 billion dollars in 2017/18. The subsidiary we study is one of the five largest IT service providers in the world and offers an extensive range of technology products, solutions, and services. In the early twenty-first century, it was common for employees in the consulting department to work remotely. These employees were often with customers, and therefore rarely in the office and thus staffed with home office contracts. New hires usually work on-site at the organization for the first few days. Getting to know their team members is challenging for newcomers as the others work from home when they are not at a customer's location.

The IT outsourcing department focuses its daily work on an on-site presence; however, alternating telework is also common. Alternating telework means that the employee has workspace within the company as well as outside the company. This is particularly helpful for the employees since this area of work requires standby duty, which means that the employees have to work on-call shifts. On-call duty is when an employee must be on standby for business purposes. The on-call duty is typically outside the regular business hours of the company, which mainly involves working at night. Thus, the person on-call can work from home. Only rarely are employees in this department offered home office contracts. Yet, a supervisor usually agrees on a home office contract if the employee has worked at the location for several years and is well integrated into the company and the department.

The research design we use is an embedded, single case study design with multiple units of analysis [21]. Within this case study, we examined the issues of interest through semi-structured dyadic interviews with pairs of a manager and their remote working employee (i.e., considered as the unit of analysis). A dyadic analysis helps to develop a richer understanding of the issues related to the remote work relationships between manager and their employee (especially when both work remotely), and the constraints and opportunities for both that underpin the success of such new working approaches. The absence of a dyadic analysis would have left important interdependencies between managers and their remote working employee unconsidered and could not have uncovered important areas of tensions between these two parties.

Figure 1 shows the segmentation of the interviewees into two main groups. One group is employees who work remotely. This group has two subunits: consulting and non-consulting. The second group covers the managers of the remote workers with two subunits as well. The distinction is necessary since a manager who belongs to the consulting department is also someone who works remotely. 

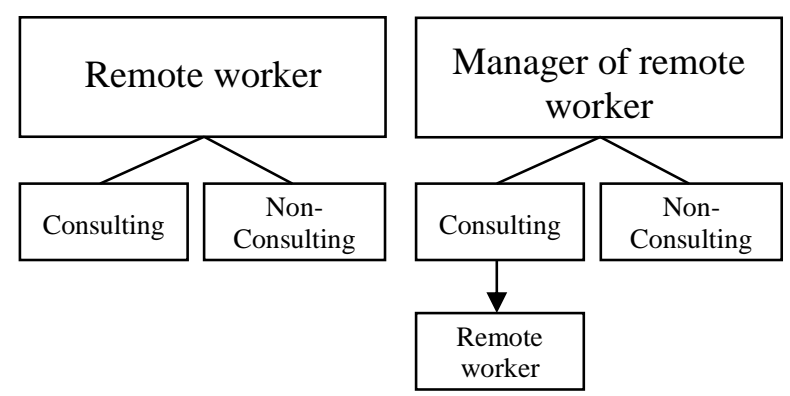

Figure 1. Groups of Interviewees

We interviewed the two groups of interviewees and as each group has subunits, which are not a case in themselves, we use an embedded design [21]. The case is named 'Remote Worker' and has four embedded units of analysis (see Figure 2).

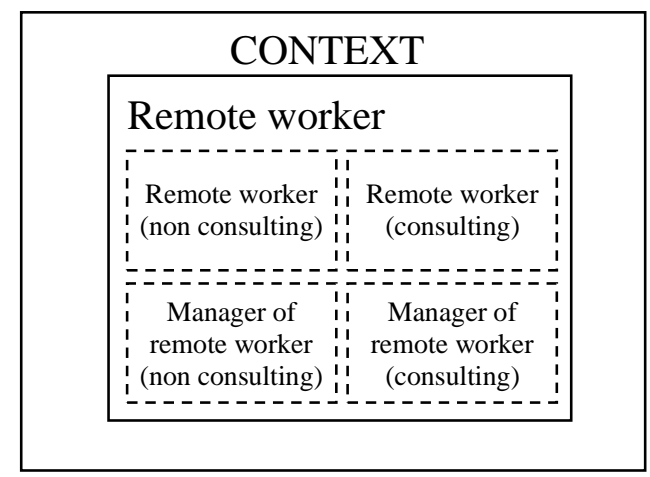

Figure 2. Case Study Design

The embedded units of analysis consist of eight remote workers and six managers: consulting (five employees, three managers) and non-consulting (three employees, three managers). The differentiation between consulting and non-consulting is important as remote workers are more common in the consulting department. The other departments do not have many remote workers.

One researcher of the author team interviewed each participant for a time period of 50-80 minutes. During the interviews, we invited participants to provide anecdotes, examples, and further details on the topics of interest. In total, we conducted 14 interviews with eight employees and six managers. We interviewed seven men and seven women. The average interviewee was 44 years old, had 17 years of professional experience in general, and worked eight years in the case organization. All interviewees were IT consultants and had at least a bachelor's degree. For more information regarding the demographic characteristics, such as age and years of (remote) working experience among the interviewees, see Table OA1, OA2, and OA3 in the Online Appendix.

\section{Data Analysis and Results}

We analysed all data with axial coding with the help of ATLAS.ti. During the evaluation process, each interview gets its coding. The codes describe relevant statements from each interviewee. The codes for managers and employees are different, as this paper strives to juxtapose the statements of both groups. After coding, the next stage is to group the codes. Following the grouping is the matching of the groups to the relevant research areas.

We begin by discussing the managers' views of home office contracts. This view should enable the reader to understand how management looks at home office regulation.

Even though the home office regulation at the organization has been in existence for many years, it is still a contentious topic. Only one of the executives we interviewed offers a home office contract during the hiring process. In contrast, a manager from the consulting department does not like to give home office contracts right away. If a home office is important for the employee, the manager decides on an individual basis, whether a home office contract is feasible. He further states that new employees can get a home office contract after they have spent a couple of months on-site. This view aligns with most of the managers' opinions. Another manager we interviewed is concerned that people working from home could be distracted with private appointments. This manager prefers to have workers nearby, ideally at the same location. However, most of the managers explain that they have no problem with telework. One manager likes the option to assign an employee to a location and agree with the individual on teleworking. Additionally, some of the managers fear that employees with no home office contract might be envious of their colleagues who do have one. The disparity between team members could negatively affect the satisfaction of the employees who do not have a home office contract. Yet, because managers see home office work as a delicate topic, they would prefer a test phase. Employees should first prove themselves suitable for working from home. Then their manager can consider giving them a home office contract.

The following subsections, we apply the case study findings to each research area identified in the literature review in Section $2^{3}$.

\subsection{Positive and Negative Aspects of Remote Work}

In Tables 1 and 2, we summarize the positive aspects of remote work mentioned by the remote workers and their managers, respectively. Five of the remote workers we interviewed like the flexibility of integrating work life and private life. One says that he uses the flexibility to

\footnotetext{
${ }^{3}$ We do not claim for comprehensiveness. Dimensions may be missed out in our case organization.
} 
make private appointments. Most explain that they do minor things at home, like doing the laundry. Some with children at home also like the flexibility to spend more time with them. One manager says that a home office has a high value for him because it contributes to his work-life balance. He also believes that the workload for remote workers in his department can be unpredictable, which is why he thinks it essential that people can manage their time freely. Another positive factor nearly each remote worker mentions is the travel time they save if they do not have to go the company; managers also agree that saving travel time is a bonus. One manager said that he also would not travel to the company's facilities if he had to travel more than an hour. Most of the remote workers use the travel time they save for working because they feel an obligation towards the company.

\begin{tabular}{|l|c|}
\hline Advantages & Mentions \\
\hline Closer to family and kids & 5 \\
\hline $\begin{array}{l}\text { Lesser distraction than on-site, } \\
\text { easier to concentrate }\end{array}$ & 6 \\
\hline Flexible day-to-day organization & 4 \\
\hline Saving costs for tax purposes & 2 \\
\hline $\begin{array}{l}\text { Time-saving because traveling to the } \\
\text { company is not needed }\end{array}$ & 8 \\
\hline Work-life and private-life integration & 5 \\
\hline Autonomous working & 8 \\
\hline
\end{tabular}

Table 1. Positive aspects of remote work: Remote workers' perspectives

The interviewees also mention the financial aspects of working remotely. Those with a company car have financial savings because they do not have to tax their way to the company as the country's laws demand. Another aspect remote workers and managers agree upon is that working from home means less distraction. A manager explains that he tends to work more effectively at home than at the office, especially, when the workspace is in an open-plan office with distractions like background noise are ever-present.

Another factor a remote worker explains is that the home office gives the ability to do the work you like. This interviewee argues that the area he lives in does not have many job opportunities, especially not in his field of business. By working remotely, he can look for the right job instead of looking for the right location.

\begin{tabular}{|l|c|}
\hline Advantages & Mentions \\
\hline See remote work as an advantage in general & 5 \\
\hline Increase in job satisfaction & 4 \\
\hline Increase in well-being & 5 \\
\hline Good concept for an autonomous worker & 5 \\
\hline Work-life and family-life integration & 4 \\
\hline
\end{tabular}

Table 2. Positive aspects of remote work: Managers' perspectives
Four out of the eight remote workers like to work from home, while two would prefer to work on-site, and two would prefer a mix of home and remote work. Each remote worker has different perceptions of remote work.

The following paragraphs focus on the negative sides of remote work. One remote worker reports that he does not like to mix work and his private life too much. He argues that both aspects can interfere with each other with adverse effects. Another says that if both aspects are mixed up, it is hard to separate them later on if the next employer might not grant the ability to work from home. Another factor is the physical availability for family and friends. One of the interviewees complains that his wife does not understand that he has to work when home. She distracts him often during the day with private issues. One of the managers states that he feels a psychological burden because he has to justify to his family and friends why he is not available for private matters when he is working from home. In Tables 3 and 4, we summarize the negative aspects of remote work mentioned by the eight remote workers and their managers, respectively.

\begin{tabular}{|l|c|}
\hline Disadvantages & Mentions \\
\hline $\begin{array}{l}\text { Lack of understanding from family/friends } \\
\text { that being home does not mean being } \\
\text { available }\end{array}$ & 4 \\
\hline Less social contact, less information & 7 \\
\hline Irregular, non-structured workday & 3 \\
\hline Work-life and private-life integration & 3 \\
\hline Too less support from manager & 3 \\
\hline
\end{tabular}

Table 3. Negative aspects of remote work: Remote workers' perspectives

Another negative aspect of remote work is the irregular and non-structured daily routine. One employee explains that he sometimes is in his pajamas until afternoon. Also, a common belief amongst non-remote workers is that employees who work from home do everything except work. A manager argues that because a remote worker is doing private things during work time, the worker might not be able to tell exactly how many hours are worked. Thus, there is the possibility that a remote worker may work fewer hours than in their contract.

One aspect remote workers and employees alike mention is the integration of new employees. If a new employee cannot spend their initial months with colleagues on-site, the individual might have difficulties getting to know the company, the processes, and colleagues. This could impact their work, as they might be less integrated or not get the right help at the right time. A manager adds that if an employee is on-site and has a problem, multiple employees might help to solve this issue and gather around the laptop of the person seeking help. Through this helping process, everyone can learn. If an employee sits at home and solves the issue, they are not expected to learn from the experience. 


\begin{tabular}{|l|c|}
\hline Disadvantages & Mentions \\
\hline Less communication & 3 \\
\hline Integration is difficult & 3 \\
\hline Performance measurement & 4 \\
\hline Networking & 3 \\
\hline Isolation & 4 \\
\hline
\end{tabular}

Table 4. Negative aspects of remote work: Managers' perspectives

One problem for managers could be the communication with remote workers. Being on-site means that managers can visually see their employees; for example, they might see someone looks sick. This insight is not as likely with remote workers. Another manager thinks that remote workers tend to anonymize themselves. He feels that they tend to use email instead of phoning someone. Using this communication channel has an impact on the social component as well. When working remotely, it is more challenging to keep up with social networks as one worker mentions. A manager adds that remote work has many negative points and that remote workers need a significant amount of self-discipline.

\subsection{Workplace and Social Isolation}

We examine the perceived workplace and social isolation of remote workers and their implications on workplace relationships. Regarding workplace isolation, one of the remote workers says that the teams use a group chat where everyone tells what they are doing. In this case, the group chat helps to decrease their feelings of isolation.

However, there are other situations in which the team is not able to integrate the remote workers sufficiently. One interviewee explains that if data center outages occur, the team is not optimally prepared to integrate remote workers efficiently for solving problems. Adding to this point, in a regular team meeting, all on-site members sit together and join a Skype with remote workers. A manager stated that this constellation causes a loss of quality for the remote worker (e.g., a feeling of exclusion), and the remote workers do not hear everything the on-site team says. The manager adds that a solution for making each team member equal could be that everyone logs into the meeting from her computer. However, this implies that the on-site team is no longer sitting together as a group.

One manager explains that when it comes to communication, exchange, or networks, a home office is not useful. A remote worker argues against this statement as he explains that there is no significant difference for him in working on-site or at home. When he sits in the office, he works on his computer without having many conversations with others. The manager of this remote worker says that this employee is not good at small talk. Thus, it depends on the individual if they experience a difference in the interactions with colleagues, depending on whether they work from home or on-site. In sum, six out of the eight remote workers miss social contacts when working remotely.

Most managers explain that they have problems communicating with their remote workers. One says that he usually addresses his remote worker if there is a particular concern, but they do not exchange small talk. A remote worker agrees. He only calls others if he has a concrete matter. Another manager adds that the phone is sometimes viewed as an artificial hurdle. Before employees use the phone, they ask their neighbors if they sit on-site, or they try to solve their problem by themselves if they are at home.

Another point, which hits managers and employees alike, is the lack of facial expressions during phone conversations. One manager reports that if he talks to his remote workers, he only hears what they say, and thus he must rely on what they tell him. If a remote worker says they are fine, he cannot distinguish whether this is true or not. A remote worker relates something similar. This worker says that when he is talking with others, he only hears what they say but does not know the person's reactions.

Furthermore, one remote worker explains that he sometimes feels left out. He gives the example of emails he receives from colleagues who announce that they are celebrating their birthday today and brought a cake for everyone. He says that the on-site people could announce things like this earlier so that people who work remotely can plan to take part as well. Another is the missing time remote workers and the on-site workers can share for private or not directly work-related things. Almost none of the remote workers call their colleagues and talk about private things. Employees who work on-site can engage in these types of conversations because they see each at work. Another manager says that he only has private conversations with his workers on-site (e.g., during lunchtime). Some remote workers mention that they especially miss the social time they spent with their colleagues. They used to sometimes join their colleagues for after work activities.

\subsection{Self-Determination}

We also examine whether remote workers feel satisfaction or frustration of their psychological needs. Overall, the autonomy a remote worker has is quite high. One remote worker explains that he would like to increase the flexibility and autonomy he has even further. He would like to work from other places like somewhere from a cottage in the Alps, for example. A manager adds that his workers are responsible for themselves and have certain seniority and professional experience, so he does not need to lead them continually. Managers and remote workers have similar perceptions. Remote workers want to have a certain degree of autonomy while their managers want them to work autonomously.

However, not all employees have the required characteristics (e.g., work experience or personality) to 
work remotely. A manager gives the example of a newly hired employee, who initially had difficulties with working from home. The individual works from an office for which he pays rent every month.

When remote workers become more autonomous, they mostly do not communicate with their managers as often as they might have before. One manager says that he has not seen one of his remote workers for a couple of months. He thinks that he might miss vital concerns the employee may have. If a remote worker is evaluating terminating her employment due to job frustrations, her manager likely has fewer opportunities to intervene.

One interviewee says that remote work requires a lot of motivation. A remote worker reports that his ambition motivates him and that neither his manager nor the company motivates him. However, another remote worker mentions that if her task is not satisfying her for a longer period, her motivation decreases. However, she also says that the quality of her task output sometimes drops if her motivation decreases. Most of the remote workers we interview seem to be intrinsically motivated. Nonetheless, one explains that he is always equally strong motivated, or unmotivated. As work is just business for him, he has a divided relationship to it.

A negative facet of work autonomy is that remote workers need to monitor themselves. They need to be aware of their overwork and need to look for compensation by themselves. One worker says that the managers often do not know what you are working on and how much time you spend. Also, many of these workers have contracts stating that their salary covers overtime. Thus, remote workers need to balance their work-life themselves.

\subsection{Support from Colleagues and Work Opportunities}

We next examine the support remote workers get from their colleagues and managers. If a worker needs help, they either need to know who to contact or know someone who can help find the right person. However, not every remote worker is well integrated into the team or the company. One says that she often does not know who to ask if she needs support as she has worked from home since the beginning of her employment. A manager adds that when a seasoned employee begins working from home, they might lose contact with their network over time because the team constantly changes. A remote worker states that if an employee is not on-site, others might see her as anonymous, which makes working together more difficult. However, a manager whose workers start working remotely from the first day has another concept of integrating his people. He and his team use a mentoring concept. Each time a new person joins the team, they get assigned a mentor who works in a similar area. The manager chooses the mentors not only for their work-topic fit but also for their social skills. The mentoring concept helps the new workers to overcome their fear of knowing who to contact. One of the remote workers, who has a mentor as well, reports some difficulties with the concept. He argues that communication is mostly asynchronous and that he often has to wait for an answer. Thus, he tries to solve most of the problems he faces by himself.

When looking at the managerial support for remote workers, the opinions about the needed degree of support varies. Many of the remote workers are highly autonomous and require less supervision and help from their managers. Some say that they only contact their managers when they have a problem. Some of the managers agree that they only contact their remote workers when there is a problem. One manager adds that it is his job to know what his people are doing. He relates that his workers can always contact him if they have a question or problem. One of the remote workers of this manager does not agree with his statement. The individual says that he has to ask the manager for a feedback meeting, but he would expect the manager to request this type of meeting. This person adds that the manager is not informed and does not know what his worker is doing. Yet, the remote worker agrees that the manager should be aware of what her worker is doing and whether remote workers face challenges.

Most of the remote workers agree that they do not miss many work opportunities. One says that either he looks for a task or simply receives them. He explains that he has been with the company for many years and that is an expert in his field. Thus, nearly everything that relates to his topics reaches him eventually. However, there are always tasks that are new to the team and the department. If remote workers lack the appropriate network, they might not be able to learn about new opportunities. A remote worker says that networks might offer information about opportunities that are of interest to him. He adds that networking typically does not take place in a remote working situation. Nonetheless, another remote worker is happy with the situation that he does not get a special task anymore. He explains that his department manager gives particular tasks only to the people he has direct access too. This deprives remote workers of opportunities to work on special tasks, which they might like, and which could help them in their career.

\subsection{Productivity and Company Obligations}

Next, we evaluate how remote workers perceive their productivity and if they feel an obligation toward the company. One of the interviewees says that her productivity is high if she has a lot to do; if she has no pressure and not many tasks, she is not productive. However, she did not relate her productivity towards an obligation. Other interviewees say that they feel a kind of obligation towards the company because they can work from home. Because of the obligation, they want to give something back to the company. This can relate to spending extra hours working or in working harder and 
more accurately on topics. One relates that he is working overtime because he sees working remotely as an advantage he has. Thus, he leaves his laptop running after his regular working time and regularly checks whether something comes in or someone needs help. However, some remote workers do not overwork. One says that he does not think that he spends much more than 40 hours a week working.

Productivity and distraction can interfere with each other. The distraction an employee has at home can be similar to the distraction an employee has on-site. A manager claims that there are often disturbing background noises (e.g., dogs barking) when he talks to remote workers. Thus, remote workers could have distractions like on-site workers

There are other interesting points in the distinction between the remote worker and the on-site worker. If a remote worker does not answer the phone because they are working intensively on something, it may appear that the remote worker is not working at all. If an on-site worker is not present at her desk for three hours, it may look like, for example, they are attending a meeting. The same principle does not apply to remote workers. A remote worker says that he has the feeling that he always needs to be present to show to others that he is working and sitting at his laptop. Nonetheless, another remote worker explains that her remote working colleagues often look busy on the surface. When she talks to her colleagues, some of them reveal that they know every news page by heart because they do not much to do and thus keep themselves busy with other things. One remote worker argues that taking advantage of working remotely harms the concept of remote work in general.

Nonetheless, managers need to evaluate the performance of their remote workers. The interviews demonstrate that managers track the performance of these workers differently. One of the managers uses workload analysis. With this analysis, he can see how many hours the worker books. Further, the manager tries to speak with every remote worker once a week to see how they are doing. Another manager uses key performance indicators, such as if he has to address escalating customer problems more and more frequently. To put it another way; if he does not hear anything from the customer for which one of his people is working, he assumes that everything is fine. Another manager evaluates the performance of his remote workers through their vacation replacements; he uses the replacement's feedback about the work to evaluate the remote worker.

One of the remote workers relays that he thought about terminating his employment contract, but he did not as he likes to have a remote working agreement and does not want to give this up. In other words, his reason to stay with the company is the contract, not the company itself. Another remote worker states that he felt considerable pressure at the beginning to deliver an excellent performance, but he does not feel this pressure anymore. It is hard to say whether the decrease in his perceived pressure has an impact on his performance or his obligation to the company.

\section{Discussion}

As demonstrated in our study, it is difficult to find common approaches to explain how remote workers can cope with their work-life situations. In general, it appears that each person handles the integration of their work life into their homes differently. However, some more or less common themes arise.

Communication is an essential component not only between colleagues but also between workers and managers. For example, if a remote worker is dissatisfied or not motivated because the work is unpleasant, the manager can only act if they know the worker is dissatisfied. In addition, communication between the remote worker and the manager is vital to avoid a drop in quality as well. However, the interviews show that direct exchange may decline over time. Remote workers and managers typically only call others if they have a specific work-related topic.

At the same time, remote workers often mention that they have less social contacts with colleagues and that they miss having these social interactions. Some remote workers feel the lack of direct contact with other employees is the most cogent point why they are not satisfied with their remote working situation and thus would prefer to work in the office. Additionally, some remote workers perceive a lack of understanding by their family and friends when they work from home.

Nonetheless, remote work has many advantages. The interviewees mention flexibility as one of the most significant advantages for remote work. People seem to like to mix their work life with their private life. Another advantage the interviewees mention is the travel time they save. Interestingly, most of these workers prefer a teleworking concept rather than a remote working concept. Not only do many managers find telework better than remote work, but half of the remote workers would prefer this as well. Nevertheless, there should also be a concept for remote work and a solution for the integration of remote workers as well. Many interviewees relate that the employee should spend the first few months, ideally even a year, on-site. Starting on-site helps the new employee to get to know their colleagues, the processes, the organization, and to build a network. After spending some time-on-site, working from home is easier for remote workers as they know who to contact if problems arise. However, an extended on-site phase, in the beginning, is not easy to realize as not every employee is willing to move to the on-site location. This loops back to the problem that the company might lack the ability to attract a skilled workforce in a broader geographical area.

However, the ICT organization has access to employees who live across the country and have the required skills because they offer remote working contracts. If a one-year stay at one location precedes 
remote work, fewer employees from more distant regions might join the organization as they do not want to move. Thus, remote work allows people to work for companies that are otherwise too distant. In addition, the elimination of the remote working concept would limit the competitiveness of the organization. Not only do employees of the ICT organization ask for remote working contracts, job candidates ask for them as well.

\subsection{Practical Implications}

During the interviews, most of the interviewees did not put much thought into the concept of remote work. Thus, some organizations should eventually do more for these workers.

New employees or those who do not much work experience should receive an elaborate work manual. This manual could contain information on what equipment remote workers can order for their home office and how the ordering process works. Further, it should contain other things workers can receive, like reimbursement for their Internet connection. Additionally, it could include relevant training for remote workers to better communicate with their colleagues to avert the negative facets of remote work like social isolation.

Managers who do not have much experience with managing remote workers likely need more guidance. For example, managers with more experience could develop best practices, which every manager with remote workers could use. These could include suggestions that managers hold team meetings regularly so that members can see each other face-to-face. The best practice document could also include suggestions for relevant training and coaching for how to effectively manage remote workers.

Furthermore, the company should promote and support greater integration with its remote workers. For example, it could make budgets available for regular team meetings. Also, most of the remote workers use their own equipment. To prevent inequality between employees, the company could equip everyone similarly.

The company must also have a well thought out remote working concept. This is necessary as more companies offer remote working opportunities. Offering remote working contracts might not be enough to attract skilled employees. Instead, the concepts should focus on the remote working employee and their integration; only then might organizations gain a competitive advantage out of offering remote working opportunities.

\subsection{Future Research and Study Limitations}

It would be interesting to investigate the psychological aspects of why employees work remotely (especially for many years) despite the many negative aspects. These remote workers mostly do not want to relinquish their opportunity to work from home as they are too comfortable with their situation.

Another factor to investigate could be remote workers' fears because they have worked in isolation for long periods. Thus, remote workers might not feel comfortable or be willing to go back to working on-site. In addition, they might also have problems with less independence should they work on-site. Further, future studies could analyze whether remote workers are better or worse team players than people who work at the same location.

Another interesting topic is the difference in work life and private life between on-site workers and remote workers. The line between the separation of work and private life might blur for all of these workers. A future study could investigate whether on-site workers or remote workers are better at separating both lives and why.

Moreover, when we consider that this study was conducted before COVID-19 it could be especially vital to examine in future studies how our results can be applied to the actual working situation in a global pandemic and how our findings could be different now given that we have a larger remote workforce (e.g., less lack of understanding of family and friends, greater challenge of social contact).

Although this small case study delivers valuable insights, some limitations of our research approach need to be acknowledged. Our results only represent a remote working concept and its related processes for one particular organization and cultural setting. The positive and negative aspects for people and the organization that we examine might be different in other organizations, industries, and countries. Moreover, other dimensions (e.g., health and wellbeing, lack of networking and career advancement opportunities) could be important in other contexts and consequently could be focused on in future research. Therefore, the generalizability of our results might be limited to a certain extent. Yet, case study methodologists insist that a study involving just one case is acceptable [22]. However, our findings regarding the different aspects of remote work for employees and manager can be logically generalized to some degree, because the underlying causal effect with respect to the interdependencies is context-independent for most organizations implementing remote working concepts.

\section{Conclusion}

Our study reveals and represents new promising insights in how remote workers (both managers and their employees) adapt differently to their working situation. Our case study puts in place an array of positive and negative aspects (such as autonomy, flexbility, lack of social contact, feelings of isolation) that should be considered when integrating such work models in organizations. Overall, our analysis emphasizes that not every employee who works remotely likes it, and thus, remote working concepts should focus more on the integration of these employees. Our study also highlights that every organization must have a well thought out remote working concept in future, as it will be required more and more from highly skilled individuals. This 
becomes even more evident and important, when we consider that this study was conducted before COVID-19. Accordingly, we provide a starting point to better understand interdependences between manager and employees in remote work models.

\section{References}

[1] A. Eckhardt, A. Giordano, F. Endter, and P. Somers, "Three Stages to a Virtual Workforce.", MIS Q. Exec., 1 (5), 18AD.

[2] M. Vansteenkiste and R. Ryan, "On psychological growth and vulnerability: basic psychological need satisfaction and need frustration as an unifying principle.", J. Psychother. Integr., 3, pp. 263-280, 2013.

[3] K. Dery, I. M. Sebastian, and N. van der Meulen, "The Digital Workplace is Key to Digital Innovation", MIS Q. Exec., 16 (2), pp. 135-152, 2017.

[4] A. Aguilera, V. Lethiais, A. Rallet, and L. Proulhac, "Home-based telework in France: Characteristics, barriers and perspectives.", Transp. Res. Part A Policy Pract., 92, pp. 1-11, 2016.

[5] T. D. Golden and A. Fromen, "Does it matter where your manager works? Comparing managerial work mode (traditional, telework, virtual) across subordinate work experiences and outcomes.", Hum. Relations, 64 (11), pp. 1451-1475, 2011.

[6] W. F. Cascio, "Managing a virtual workplace", Acad. Manag. Perspect., 14 (3), pp. 81-90, 200AD.

[7] G. DeSanctis, "Attitudes toward telecommuting: implications for work-at-home programs", Inf. Manag., 7 (3), pp. 133-139, 1984.

[8] C. A. Grant, L. M. Wallace, and P. C. Spurgeon, "An exploration of the psychological factors affecting remote e-worker's job effectiveness, wellbeing and work-life balance.No Title", Empl. Relations, 35 (5), pp. 527-546, 2013.

[9] B. Wellman, J. Salaff, D. Dimitrova, L. Garton, M. Gulia, and C. Haythornthwaite, "Computer Networks as Social Networks: Collaborative Work, Telework, and Virtual Community.", Annu. Rev. Sociol., 22 (1), pp. 213-238, 1996.

[10] L. M. de Menezes and C. Kelliher, "Flexible Working, Individual Performance, and Employee Attitudes: Comparing Formal and Informal Arrangements.", Hum. Resour. Manage., 56 (6), pp. 1051-1070, 2017.

[11] K. A. Eddleston and J. Mulki, "Toward Understanding Remote Workers' Management of Work-Family Boundaries: The Complexity of
Workplace Embeddedness.", Gr. Organ. Manag., 42 (3), pp. 346-387, 2017.

[12] A. R. Koch and C. Binnewies, "Setting a good example: supervisors as work-lifefriendly role models within the context of boundary management.", J. Occup. Health Psychol., 20 (1), pp. 82-92, 2015.

[13] M. A. Orhan, J. B. Rijsman, and G. M. van Dijk, "Invisible, therefore isolated: Comparative effects of team virtuality with task virtuality on workplace isolation and work outcomes.", Rev. Psicol. del Trab. y las Organ., 32 (2), pp. 109-122, 2016.

[14] A. E. Colbert, J. E. Bono, and R. K. Purvanova, "Flourishing via Workplace Relationships: Moving Beyond Instrumental Support.", Acad. Manag. J., 59 (4), pp. 1199-1223, 2016.

[15] V. J. Morganson, D. A. Major, K. L. Oborn, J. M. Verive, and M. P. Heelan, "Comparing telework locations and traditional work arrangements.", J. Manag. Psychol., 25 (6), pp. 578-595, 2010.

[16] G. W. Marshall, C. E. Michaels, and J. P. Mulki, "Workplace isolation: Exploring the construct and its measurement.", Psychol. Mark., 24 (3), pp. 195-223, 2007.

[17] R. M. Ryan and E. L. Deci, "Self-determination theory and the facilitation of intrinsic motivation, social development, and well-being.", Am. Psychol., 55 (1), pp. 68-78, 2000.

[18] T. Vander Elst, A. van den Broeck, H. de Witte, and N. de Cuyper, "The mediating role of frustration of psychological needs in the relationship between job insecurity and work-related well-being.", Work Stress, 26 (3), pp. 252-271, 2012.

[19] S. J. Perry, C. Rubino, and E. M. Hunter, "Stress in remote work: two studies testing the DemandControl-Person model.", Eur. J. Work Organ. Psychol., 27 (5), pp. 577-593, 2018.

[20] M. Chiniara and K. Bentein, "Linking servant leadership to individual performance: Differentiating the mediating role of autonomy, competence and relatedness need satisfaction.", Leadersh. Q., 27 (1), pp. 124-141, 2016.

[21] R. K. Yin and D. T. Campbell, Case study research and applications: Design and methods., SAGE Publications, Inc, Thousand Oaks, California, 2018.

[22] S. Sarker, X. Xiao, and T. Beaulieu, "Qualitative Studies in Information Systems: a Critical Review and Some Guiding Principles.", MIS Q., 37 (4), pp. iii-xviii, 2013.

[23] A. Richter, "Locked-down digital work.", J.Infor. Manag. 102157, 2020. 